\title{
Fundamentos psicanalíticos na construção da subjetividade na Psicose
}

\author{
Psychoanalytical fundamentals in the construction of subjectivity in Psychosis \\ Fundamentos psicoanalíticos en la construcción de la subjetividad en Psicosis
}

Recebido: 26/07/2021 | Revisado: 31/07/2021 | Aceito: 02/08/2021 | Publicado: 07/08/2021

\author{
Cristiano Matana \\ ORCID: https://orcid.org/0000-0002-6194-6209 \\ Universidade Franciscana, Brasil \\ E-mail: crismatana@terra.com.br \\ Silvio A. Lopes Iensen \\ ORCID: https://orcid.org/0000-0001-5734-7214 \\ Universidade Franciscana, Brasil \\ E-mail: silvioiensen@gmail.com
}

\begin{abstract}
Resumo
Este trabalho de pesquisa sobre a temática da psicose segue uma linha psicanalítica de estudos, com caráter qualitativo de revisão bibliográfica narrativa. O mesmo investiga os fundamentos da clínica das psicoses, trazendo um estudo do caso Schreber feito por Freud, como a leitura de estudiosos que revistaram suas obras a fim de compreender melhor os seus desdobramentos. Outro objetivo é verificar a dimensão da transferência ligada ao manejo clínico, o qual tange a relação analista-paciente, como um outro princípio norteador para o tratamento da psicose. Sabe-se que a transferência faz parte tanto da clínica neurose, como da psicose. Mas é na clínica da psicose, que Freud afirma que ela é negativa. Esse "obscurecimento" por esta palavra usada por Freud, é o que vai levar muitos psicanalistas a se debruçarem nessa temática. Sobre o manejo, nas entrelinhas do caso Schreber, Freud dá algumas indicações. Mas, os avanços significativos vêm nas obras de autores pós-freudianos interessados em desbravar o terreno "árido" das psicoses. Considerando a soma dessas temáticas, percebe-se a possibilidade de tratamento para estes pacientes, como um saber renovado sobre o sujeito da loucura. Aqui, o "louco", o psicótico, como sujeito em sua, em "nossa" história, a fim de assegurar um lugar que lhe é próprio - não por merecimento de um estado de "sanidade", cuja sociedade lhe confere como justo, mas pelo que lhe é de direito.
\end{abstract}

Palavras-chave: Psicanálise; Psicose; Transferência; Manejo.

\begin{abstract}
This research work on the theme of psychosis follows a psychoanalytic line of studies, with a qualitative character of narrative bibliographic review. The same investigates the foundations of the clinic of psychoses, bringing a study of the Schreber case made by Freud, as the reading of scholars who reviewed his works in order to better understand their consequences. Another objective is to verify the dimension of transference linked to clinical management, which concerns the analyst-patient relationship, as another guiding principle for the treatment of psychosis. It is known that transference is part of both clinical neurosis and psychosis. But it is in the clinic of psychosis that Freud claims that it is negative. This "obscuration" by this word used by Freud is what will lead many psychoanalysts to focus on this theme. About handling, between the lines of the Schreber case, Freud gives some indications. However, significant advances come in the works of post-Freudian authors interested in breaking into the "dry" terrain of psychoses. Considering the sum of these themes, the possibility of treatment for these patients is perceived, as a renewed knowledge about the subject of madness. Here, the "crazy", the psychotic, as a subject in his, in "our" history, in order to ensure a place of his own - not for the sake of a state of "sanity", whose society grants him as fair, but for what is rightfully his.
\end{abstract} Keywords: Psychoanalysis; Psychosis; Transfer; Management.

\section{Resumen}

Este trabajo de investigación sobre el tema de la psicosis sigue una línea de estudios psicoanalíticos, con un carácter cualitativo de revisión bibliográfica narrativa. El mismo investiga los fundamentos de la clínica de las psicosis, aportando un estudio del caso Schreber realizado por Freud, como la lectura de los estudiosos que revisaron sus obras con el fin de comprender mejor sus consecuencias. Otro objetivo es verificar la dimensión de la transferencia ligada al manejo clínico, que concierne a la relación analista-paciente, como otro principio rector para el tratamiento de la psicosis. Se sabe que la transferencia es parte tanto de la neurosis clínica como de la psicosis. Pero es en la clínica de la psicosis donde Freud afirma que es negativa. Este "oscurecimiento" por esta palabra utilizada por Freud es lo que llevará a muchos psicoanalistas a centrarse en este tema. Sobre el manejo, entre líneas del caso Schreber, Freud da algunas indicaciones. Sin embargo, se producen avances significativos en las obras de autores posfreudianos interesados en irrumpir en el terreno "seco" de las psicosis. Considerando la suma de estos temas, la posibilidad de tratamiento para estos pacientes se percibe, como un conocimiento renovado sobre el tema de la locura. Aquí, el "loco", el psicótico, 
como sujeto en la suya, en "nuestra" historia, para asegurarse un lugar propio, no por un estado de "cordura", cuya sociedad le concede como justa. sino por lo que es legítimamente suyo.

Palabras clave: Psicoanálisis; Psicosis; Transferencia; Gestión.

\section{Introdução}

A Psicanálise, criada por Freud, é a ciência que começa a trabalhar de modo diferente do estabelecido desde o século XIX. Ela contribui para a compreensão de um sujeito com sofrimento psíquico, criando conceitos que ampliam a visão sobre as psicopatologias e complexiza o entendimento que se tinha na época. Quando se fala de um "sujeito com sofrimento psíquico" não se reduz ao sujeito da neurose, mesmo que esta clínica seja hoje uma das mais estudadas e refletidas no mundo acadêmico. Muito pelo contrário, com o advento da clínica psicanalítica das psicoses (praticamente justa posta a das neuroses), observando sua evolução, começou-se a dar "voz" ao sujeito da "loucura", inclusive a seus sintomas - tonando bem distinguíveis o tipo de clínica voltada para o sujeito neurótico. E quanto mais se avançou nessa compreensão e distinção, mais adequado foi sendo o tratamento possível a este sujeito da "loucura".

Assim, que ao propor a temática da psicose por esse trabalho, quer-se possibilitar um entendimento e relevância mais equânime se se for pensar a disparidade dos estudos em relação a neurose. Ademais, ressaltar, sim, que o tratamento é possível, mas de uma outra ordem em relação ao tratamento da neurose. Por esses caminhos de base, dois aspectos sobre o tema da psicose serão aprofundados: o primeiro será uma busca na psicanálise dos fundamentos da clínica - fundamentos como a descrição conceitual que foi servindo de alicerce para se poder compreender e diagnosticar a Psicose. Nesse sentido, o capítulo primeiro será um olhar para a psicose a partir da teoria psicanalítica de Freud, bem como outros autores que ajudaram que essas construções fossem ampliadas.

O segundo aspecto, buscará verificar a importância da dimensão transferencial na clínica das psicoses, como suas peculiaridades na relação paciente-analista. Estas peculiaridades são muito importantes de serem pontuadas, pois, a dimensão transferencial na psicanálise não é restrita ao campo da psicose. O resultado disto possibilitará que o leitor veja mais claramente os efeitos benéficos da transferência, quando bem estabelecida e compreendida, na melhora clínica de pacientes, associada ao manejo clínico.

Autores pós freudianos resgatam o legado do "Pai" da Psicanálise, especialmente quando retomam o caso Schreber. Este caso, será de suma importância para se observar os avanços na compreensão da Psicose, distinguindo-a do tema da neurose. A importância da relação transferencial do sujeito da psicose na clínica é outro assunto de relevância. O diagnóstico da psicose, conforme Calligaris (2013), se estabelece na transferência, contribuindo, assim, para compreender o sujeito para além de um sintoma, muito embora, os fundamentos ajudem na formulação do diagnóstico.

\section{Metodologia}

O presente trabalho caracteriza-se como pesquisa de abordagem qualitativa de revisão bibliográfica. Para Minayo (2003), pesquisa qualitativa é a que leva em consideração aspectos particulares da realidade estudada. A autora estabelece que nesse tipo de pesquisa trabalha-se com fatores não quantificáveis, assim, leva-se em consideração aspectos subjetivos do fenômeno pesquisado. Gil (2006, p. 44) afirma que a pesquisa bibliográfica “[...] é desenvolvida com base em material já elaborado, constituído principalmente de livros e artigos científicos”.

Rother (2007, p. v) assevera a definição de revisão bibliográfica como uma forma de pesquisa que se utiliza da obtenção de resultados, os quais podem ser encontrados em livros, artigos científicos, teses e dissertações. A mesma autora indica que a revisão bibliográfica narrativa constitui-se de análise da literatura de livros, artigos de revistas “[...] na interpretação e análise 
crítica pessoal do autor..."; que “[...] artigos de revisão narrativa são publicações amplas, apropriadas para descrever e discutir o desenvolvimento ou 'estado da arte' de um determinado assunto sob o ponto de vista teórico ou contextual".

Nesse sentido, o presente trabalho seguirá essa orientação metodológica narrativa de Rother (2007), investigando dentre as diversas fontes bibliográficas citadas, no contexto da psicanálise, o tema sobre a psicose; mais especificamente, os fundamentos e o percurso histórico dessa clínica, como também a dimensão transferencial.

\section{Resultados e Discussão}

\subsection{O conceito e os fundamentos da psicose para a psicanálise}

O conceito de psicose para Psicanálise, em uma explanação mais teórica, referencia-se a partir de seu "Pai" - Freud, trouxe elementos muito importantes para caracterizar esse fenômeno. O termo "Psicose" foi usado pela primeira vez no ano de 1844, em Viena, num curso de psiquiatria, remetendo-se à explicação de qualquer tipo de doença mental - de qualquer origem - presente num indivíduo. Mas, foi somente no século XX que esta classificação é revista, ou seja, as neuroses e doenças mentais de causas físicas (orgânicas) foram excluídas da mesma categoria das psicoses (Tenenbaum, 2010).

Quando se chega a Freud (1856 a 1939), é nesse contexto que a psiquiatria se desenvolve para tratar das doenças mentais, fundamentadas na escola descritiva francesa, onde ele próprio estuda, com a clínico-etiológica alemã, tendo como escopo o Empirismo e a Fenomenologia. Como neurologista, os fenômenos mentais foram matéria de estudos constantes e, no início destes, a fenomenologia lhe ajudou em suas concepções nosográficas das doenças, seja das neuroses, como das psicoses (Briggs \& Rinaldi, 2014).

Continuando com estes autores, observa-se que estas classificações nosográficas se deram no início, primeiramente, como neuropsicoses (mais tarde, psiconeuroses) de defesas para designar tanto a neurose quanto a psicose e a Parafrenia (a partir do caso Schreber). Quinet (2018, p. 4), diz que Freud, no ano de 1894, no artigo "Psiconeuroses de defesa", "[...] afirmava que existe na psicose uma espécie de defesa muito mais enérgica e eficaz que na neurose. Esse mecanismo consiste no seguinte: o eu rejeita (Verwerfung), a representação insuportável como se esta jamais tivesse alcançado o eu."

Para Laplanche e Pontalis (2016), se referindo ao termo Parafrenia, apesar de ter sido usado primeiramente por Kraepelin (antes de Freud, entre 1900 e 1907), serviu para designar as psicoses associadas a desorganização mental do ego como a paranoia e a demência precoce. De toda forma, a percepção freudiana, fenomenológica, é posteriormente deixada parcialmente por uma concepção que parte da dinâmica mental, especialmente a partir do caso Schreber (Freud, 1911/2010).

No ano de 1891, em suas cartas dirigidas a Wilhelm Fliess, Freud começou seus estudos sobre as afasias e as relações desta com a psicanálise, ainda em germe (Freud, 1891/2016). Não foi só a partir de uma concepção anatômica e topográfica das afasias; percebeu que havia uma distinção significativa que tornava tudo diferente para a compreensão destas em casos, por exemplo, de histeria. Nesta última, apesar de alguns sintomas repercutirem na parte motora do indivíduo, como nas afasias, sua relação não está associada a isto, ou seja, pelo fato de não haver correspondência com alguma lesão neurológica. Percebe-se o salto que Freud deu para que seus estudos se desenvolvessem a partir de uma dinâmica do aparelho psíquico, distinguindo a psiquiatria da psicanálise. Tenenbaum $(2010$, p. 17) traz a informação de que "[...] alguns problemas surgiram da aplicação desse modelo na compreensão dos fenômenos mentais presentes nos quadros de psicóticos".

Na evolução da clínica psicanalítica por Freud, dois casos - Ana O (Bertha Pappenheim - atendida por Breuer (1880 a 1882) e, mais tarde, em 1911, caso Schreber, apesar de que não foram seus pacientes, o ajudaram a confirmar algumas de suas maiores teses, dentre elas, de que as bases estruturantes, tanto da neurose obsessiva, quanto da paranoia, advinham de um fenômeno bem específico, relacionado com o autoerotismo (Laplanche \& Pontalis, 2016). Em meados de 1895, Freud tinha já mencionado que a diferença entre a paranoia e a obsessão, encontrava-se no fato de que na primeira as recriminações são projetadas no mundo exterior e, na segunda, elas se mantêm no mundo interior - recalcadas (Quinet, 2018). Pode-se pensar que 
apesar do modelo de trabalho freudiano ser baseado na investigação da neurose histérica, há um grande avanço para a compreensão das psicoses.

A distinção entre paranoia e obsessão é muito pertinente, à considerar que o caso de Ana $\mathrm{O}$, não necessitando aqui defini-lo na sua inteireza, se não para escrever o quanto estava evoluindo a compreensão e ao mesmo tempo diferenciação progressiva entre as neuroses e psicoses, trazia um misto entre estados de alteração de consciência e outros com sintomatologia motora, além de alterações de humor, com intensa ansiedade (Tenembaum, 2010). Assim que, a complexidade do mesmo e a falta de um estudo nosográfico mais pormenorizado, ao menos até este momento da vida de Freud, faz com que ele entenda este caso de histeria e seus sintomas, especialmente de confusão mental (ou absense, na época), como uma psicose aguda (servindo como equivalente a um acesso), o que seria classificado como confusão mental alucinatória, estados agudos de histeria aguda e de psicose histérica (Tenenbaum, 2010).

Santos e Oliveira (2012, p. 75) ajudam a melhor esclarecer tais conceitos, os quais serão imprescindíveis pela diferenciação mais elucidatória entre a neurose e a psicose e, esta última, apontada por Freud, singularmente, no caso Schreber.

Por essa razão, em lugar de um sintoma conversivo no corpo (histeria) ou de ideias obsessivas na mente (neurose obsessiva), o retorno do recalcado na psicose dar-se-ia sob a forma de pensamentos proferidos pelas vozes que o sujeito acredita escutar e que atribui a outras pessoas. O eu precisa acomodar-se a esse fenômeno alucinatório, mas só pode fazê-lo pagando o preço de romper com a realidade.

O caso Schreber parece ter sido o que mais evidenciou este fenômeno da psicose. Lembrando que Freud não teve contato diretamente com o paciente, se não, em 1909, ou seja, seis anos depois da publicação original do caso - em 1903 “Memórias de um doente dos nervos", quando começa seus estudos sobre o referido (Nasio, 2001). E o mais notável quando Freud propõe seus escritos sobre Schreber, é que ele

[...] apoderou-se resolutamente dessa patologia, e a contribuição que ele trouxe nada mais teve a ver com a clínica psiquiátrica da época. As 'Notas psicanalíticas sobre um relato autobiográfico de um caso de paranoia' foi o primeiro grande texto de Freud dedicado à psicose (Nasio, 2001, p. 44).

Em 1909, conforme Nasio (2001), Freud dentro de suas leituras de um estudo psicodinâmico da mente humana, percebe o quanto esse caso específico de Schreber poderia embasar suas teses, uma delas, a teoria das pulsões, dando-lhes fundamentos para estas, especialmente em observações que pudessem trazer elementos que tornassem mais distinguíveis os casos de neurose e psicose. O mesmo autor menciona três razões de Freud para estudar esse caso de paranoia, ao mesmo tempo em que aparecem suas teses: 1) Embasar mais solidamente a teoria das pulsões; 2) Elaborar a teoria do narcisismo (já então em processo de construção, e que representa uma das partes essenciais da psicanálise, ou seja, o 'eu' tomado como objeto libidinal); 3) Construir uma teorização da psicose.

Ainda, seguindo o pensamento de Nasio (2001), Daniel Paul Schreber, de família burguesa, nasceu em 1842, seu pai era médico e educador, com base religiosa oriunda do protestantismo. O autor relata, ainda, que Schreber teve dois irmãos, sendo que o mais velho se suicidou aos 38 anos de idade, com diagnóstico de uma psicose evolutiva. Uma outra irmã, mais nova, faleceu com doenças mentais. Schreber foi um homem que ascendeu ao poder político na Saxônia por sua elevada capacidade, tornando-se doutor em Direito e Juiz da Corte de Apelação (1893 - 51 anos). Segundo Freud (1911/2010), a primeira internação se deu aos 42 anos, sendo diagnosticado com hipocondria grave. Seu restabelecimento durou por 8 anos. Depois de sua nomeação à Corte de Apelação, antes de assumir suas funções, que alguns fenômenos psíquicos tornaram-se mais claros, mostrando sua natureza paranoica. Nasio (2001, p. 44) afirma que Schreber, 
Antes mesmo de assumir suas funções, sonhou diversas vezes que estava novamente enfermo. Certa manhã, em estado de semivigília, ocorreu-lhe a ideia de que "seria muito bom ser uma mulher submetendo-se ao coito". Essa ideia foi prontamente rechaçada, segundo suas palavras, com extrema indignação.

Meses depois da nomeação, um segundo desmoronamento anunciou-se, acompanhado por insônias que foram-se agravando e sensações de amolecimento cerebral. Depois, apareceram ideias de perseguição e de morte iminente, assim como uma extrema sensibilidade ao barulho e à luz. Mais tarde, surgiram alucinações visuais e auditivas: ele se via morto e decomposto, atingido pela peste e pela lepra, com o corpo submetido a manipulações repugnantes e sofrendo os mais assustadores tratamentos. Essas manifestações o faziam mergulhar por horas a fio num estado de sideração e de estupor alucinatório. Schreber chegou a desejar a morte e, em várias ocasiões, tentou suicidar-se. Com o tempo, as ideias delirantes coloriram-se de misticismo: relações diretas com Deus e aparições milagrosas.

Neste quadro clínico breve de Schreber, Nasio (2001) aponta dois aspectos que podem ser colocados em relevo e ao mesmo tempo associados que, aliás, serão as bases que denotarão a estrutura psicótica do paciente: Paranoia (perseguição) e delírio. Para Tenembaum (2010), sobre a paranoia, infelizmente Freud não conseguiu se ater exaustivamente, a fim de poder melhor explicar o sentido e a relação desta com a psicose de Schreber, muito pela insuficiência de dados biográficos e familiares.

Freud (1911/2010) afirma que Schreber sentia-se perseguido, ameaçado por Deus porque, segundo ele, depois de ter criado tudo, apenas Ele comunica-se com as almas dos que morrem e com alguns seres humanos altamente dotados de capacidades. Schreber era um desses especiais, no seu delírio - se não o maior, como o Filho de Deus, Jesus Cristo. Mas a ameaça de Deus à Schreber, é porque ele atrai esta força poderosa para si mesmo (pela excitação demasiada), o que, justificaria os sofrimentos e perseguições que ele tem passado, quase chegando ao aniquilamento físico e mental (Nasio, 2001).

Seguindo este mesmo autor, ao referir que o sofrimento impingido por Deus, tanto por meio de suas boas ou más ações (milagres), até em usar o Dr. Flechsig - " [...] autor de todas as perseguições..., e ele continua a instigá-las ao longo de toda a doença" (Freud, 1911/2010, p. 51) - para cumprir seus objetivos, nada mais seria do que uma forma para que seus "raios" pudessem conseguir se soltar de Schreber. Na relação com Deus, há uma espécie de ambiguidade, pois o mesmo Deus que o faz sofrer e o persegue, é o mesmo identificado como o "Deus Sol” tanto de glória, como de virtudes extraordinárias (Nasio, 2001). Até aqui, num breve panorama, foi uma ilustração do que Freud escreve: "Até agora tratamos do complexo paterno que domina o caso Schreber e da fantasia ou desejo central da doença” (Freud, 1911/2010, p. 78).

A partir disso, percebe-se a busca por uma certa diferenciação entre neurose e psicose, sendo que em muitos casos de neurose, a paranoia pode estar presente. Freud (1911/2010, p. 78-79):

Temos de buscar a especificidade da paranoia (ou da demência paranoica) em outra coisa, na forma peculiar assumida pelos sintomas, e nossa expectativa é de que o responsável por ela não serão os complexos, mas o mecanismo da formação de sintomas ou da repressão. Diríamos que o caráter paranoico está em que, para defender-se de uma fantasia de desejo homossexual, rege-se precisamente com um delírio persecutório de tal espécie.

Mesmo que autores como Tenenbaum (2010, p. 27) mencionem que Freud tenha reduzido por demais esta questão da psicose ao campo de causa da homossexualidade, ao considerar que a existência de uma relação causal não pode ser estrita a isso, nem unicamente como efeito ou consequência da mesma (causa), o contributo de Freud foi em escrever que por mais semelhança que haja entre paranoia e neurose como “[...] expressões resultantes da luta defensiva contra a emergência (consciência) de desejos (fantasias) amorosos ou agressivos dirigidos a pessoas que representam um genitor, impulsos estes, é bom que se diga, desencadeados (regressivamente) por problemas psicológicos atuais".

Nesse sentido, pode-se pensar que a paranoia se distinguiria, e seria uma das principais peculiaridades, pelo conflito de estar sempre ligado com o genitor do mesmo sexo da pessoa. Nasio (2001) menciona que a teoria do recalcamento aplicada à neurose não seria tão suficiente para dar conta da paranoia, levando Freud a fazer uma "mistura" entre a teoria do recalcamento e do narcisismo. Mas como ficou estabelecida estas junções teóricas?

Conforme o mesmo autor (Nasio, 2001, p. 58), na 
[...] paranoia, o recalcamento consistiria num desligamento da libido, parcial ou geral. A libido anteriormente ligada a objetos externos volta-se para o eu. Esse processo, qualificado de silencioso, seria a etapa do recalcamento propriamente dito, enquanto o delírio seria a expressão de um retorno do recalcado, reconduzindo a libido aos objetos que ela havia abandonado.

Ainda no contexto da primeira teoria do aparelho psíquico, a libido vai ocupar um destaque na obra Freudiana "Sobre o Narcisismo: uma introdução", de 1914, o que incidirá numa melhor compreensão das principais bases psicanalíticas sobre o tema das psicoses. Nesse texto, Freud

[...] define "introversão" como sendo a retirada da libido da realidade com posterior reinvestimento nos objetos internos, fenômeno limitado às neuroses, ao passo que o narcisismo é definido como a retirada da libido da realidade com posterior reinvestimento no ego para, finalmente, ser reinvestida delirantemente na realidade, etapa característica das psicoses (Tenenbaum, 2010, p. 34).

Segundo Nasio (2001), no caso de Schreber, tem-se ilustrada essa retirada da libido da realidade, mas não se quer dizer eliminação da realidade. No entanto, essa mesma realidade anteriormente existente, é percebida como sombra, dando espaço para uma realidade alterada pelo próprio ego, por exigência do id, expressão dela nos seus delírios. No caso da neurose, “[...] o ego, obedecendo às exigências da realidade (e do superego), recalca as reivindicações pulsionais" (Laplanche \& Pontalis, 2016, p. 392).

A partir da afirmação destes autores, vê-se o passo adiante que Freud deu em relação a Breuer, pois ao mesmo tempo que presta atenção a este sintoma manifesto em Schreber (delírio), peculiar da psicose, consegue perceber que os motivos do sujeito seguem uma lógica do inconsciente, tornando-o de alguma forma traduzível por estas manifestações clínicas. Assim, pode-se pensar o quanto o pensamento freudiano mantém a compreensão dos fenômenos psíquicos baseados na metapsicologia. Para Nasio (2001, p. 52), Freud deu crédito ao sujeito da psicose ao mesmo tempo em que deu aos seus sintomas, enquanto Breuer “[...] achava que não se podia confiar, de maneira alguma, nas afirmações dos doentes paranoicos”. Para Laplanche e Pontalis (2016) Freud dá-se conta de poder percorrer a evolução da própria doença, e quando se chega no delírio, sistematizá-lo seria poder seguir o fio condutor da própria libido que atravessa o sujeito da psicose apontando para sua origem, que, posteriormente, Lacan vai afirmar estar no postulado da Forclusão do nome do Pai ${ }^{1}$

Freud (1911/2010, p. 24), no caso Schreber, quando começa a traçar o histórico clínico do paciente e suas manifestações a partir dos eventos delirantes, não só vai tentar sistematizá-los, ressaltando a importância de uma sábia leitura destes, mas também melhor definir o alcance restrito da psiquiatria se comparada com o alcance maior da psicanálise no tratamento da psicose.

O interesse do psiquiatra por tais formações delirantes se esgota, normalmente, ao constatar a operação do delírio e sua influência na vida do paciente; seu espanto não marca o início de sua compreensão. Já o Psicanalista, partindo de seu conhecimento das psiconeuroses, supõe que mesmo formações mentais tão extraordinárias, tão afastadas do pensamento humano habitual, tiveram origem nos mais universais e compreensíveis impulsos da vida psíquica, e gostaria de conhecer tanto os motivos como as vias dessa transformação. Com esse propósito, ele buscará se aprofundar na história do desenvolvimento e nas particularidades do delírio.

Nesse sentido, pode-se compreender que esse fragmento freudiano demarca fronteiras entre a psiquiatria e o entendimento próprio da psicanálise chamando para esta última uma compreensão avançada a respeito da função do delírio na psicose, a saber: a metapsicologia freudiana. Segundo Tenenbaum (2010, p. 32-33), “[ ...] o que a psiquiatria considera sintoma,

\footnotetext{
${ }^{1}$ Calligaris (2013, p. 32) menciona a raiz desse conceito - que por hora é suficiente aqui: “[...] como vocês sabem é um termo jurídico que implica o fato de que alguma coisa está forcluída, quer dizer, que não se pode mudar mais - preclusão...”.
} 
Freud descreve como uma modificação do ego; para ele, a psicose instalada nada mais é do que o resultado dessas modificações adaptativas do ego à experiência de seu aniquilamento". E a formação delirante do paciente, e no caso de Schreber, havia uma predominância maior, em termos de projeção sobre a alucinação, indicando uma certa distinção de teorias nosográficas de Breuer e Jung, por exemplo. E onde estava esta distinção em Freud? Segundo Nasio (2001), é exatamente em separar o campo das paranoias e o das demências precoces. E é aqui, que Freud propõe o termo, julgando mais adequado, "Parafrenia" em substituição ao das demências precoces. O termo Parafrenia serviria para melhor caracterizar um paciente com "uma mistura de traços paranoicos e esquizofrênicos" (Nasio, 2001, p. 52).

O detalhe no caso de Schreber, é que há um enlace nessa "desordem" do paciente, perceptível para Freud, que deverse-ia procurar objetivar com maior agudeza clínica, sobretudo e, novamente se enfatiza, na observação do quadro delirante, pois o "[...] delírio é uma tentativa de cura" (Nasio, 2001, p. 54). Ainda, conforme Nasio (2001), o delírio seria a voz da "razão" do sujeito da loucura - constituída no real. No entanto, Calligaris (2013, p. 83), em acréscimo, vai dizer que o polo central que organiza a metáfora delirante desse sujeito, que se expressa no real, “[...] não está simbolizável” - o que traria um desafio muito maior à psicanalise. A partir disso, entende-se que esse não "simbolizável", não quer dizer o fechamento absoluto de Schreber em seu próprio ego, muito pelo contrário, podem ser as instâncias delirantes que se incluem num processo terapêutico ao próprio paciente. Nasio (2001, p. 55) afirma:

Ali onde se inscreve a passagem ao ato no esquizofrênico encontramos, em Schreber, um tratamento progressivo pelo delírio. Ele tentou elaborar uma construção no lugar da construção edipiana. O pai tornou-se cósmico - o sol - e divino. A feminilidade só era possível se fosse absoluta: ser mulher de Deus. Para ele, essa era uma maneira de aceitar o que se impunha de fora para dentro, de encontrar uma razão para essa coerção, inscrevendo-a numa exigência universal e divina. No final das contas, continuava a ser uma maneira de recusar a falta.

Segundo Tenembaum (2010), infelizmente, por insuficiências documentais do caso Schreber, que poderiam levar Freud a melhor especificar a psicose, e não somente alguns sintomas dela como a paranoia e o delírio, incluindo algumas análises descritas, tem-se um "corte", mas não um fim de suas grandes bases teóricas que melhor possibilitariam o entendimento da mesma. Algumas dessas obras, em especial, marcaram fortemente sua compreensão, já fazendo parte de sua $2^{\mathrm{a}}$ tópica: "Neurose e Psicose" e "A perda da realidade na neurose e psicose", ambas de 1924.

Sabe-se que a Psicanálise, a partir de Freud, foi evoluindo em constantes avanços teóricos com autores pós freudianos. Muitos contribuíram para que a Psicanálise continuasse a ser vigente como uma possibilidade de leitura sobre o sofrimento humano, que nunca pode ser estudado distante das transformações culturais. Burgararelli e Santiago (2009, p. 144), em seu texto "A psicose de Lacan a Freud", observam que as teorias freudianas

[...] partilham dos pressupostos oriundos de estudos sobre as neuroses. Ainda que tenha vislumbrado elementos indicativos de especificidades no mecanismo psíquico das psicoses, Freud insistiu, por muito tempo, em teorizá-las a partir de referências advindas de suas formulações sobre a neurose. Ele não foi capaz de formular, precisamente, o mecanismo psíquico da psicose.

E é justamente neste ponto que Lacan faz esse retorno a Freud, trazendo elementos que estruturem melhor a teoria sobre as psicoses, como seu tratamento. Entendendo que as construções primeiras de Freud não foram vistas por Lacan em oposição às suas, mas de uma base complementar aos elementos faltantes, dentre eles, "[...] de considerar a psicose em sua especificidade estrutural" (Burgarelli \& Santiago, 2009, p. 145).

Nesse sentido, percebe-se o caminho bastante complexo proposto por Lacan, o qual serviu-se da linguística estrutural, de conceitos como significado e significantes (este último com primazia em sua teoria). Para Lacan (1955-1956/1988), ao reler o caso Schreber, aponta para o elemento faltante, foracluído, cuja expressão é "verificável” pelo aspecto da linguagem. 
A respeito de uma expressão empregada por Schreber, dizendo que as vozes lhe assinalam que lhes falta alguma coisa, eu fazia notar que tais expressões não surgem sozinhas, que elas nascem do curso da história da língua, e num nível de criação bastante elevado para que isso esteja precisamente em um círculo interessado pelas questões da linguagem. Essas expressões parecem derivar de modo bem natural da arrumação dada do significante, mas o seu aparecimento em determinado momento pode ser historicamente verificado" (Lacan, 1955-1956/1988, p. 140).

Entende-se que o conceito da forclusão do nome do Pai, tem importância fundamental no tangente à estrutura psicótica, delineada pela teoria freudiana. Esta explicação remete, por um certo viés, ao campo da neurose (pelo mecanismo de recalque), haja vista que as formulações inicias de Freud, no édipo, serviram para traçar o "negativo" característico da psicose (Burgarelli \& Santiago, 2009). Para Aragão e Ramirez (2004, p. 89), o pensamento lacaniano faz referência ao édipo na neurose. É por esta inscrição que o sujeito neurótico entra no mundo do simbólico e,

Por ser simbólica, é possível operar a função paterna como uma metáfora; assim, o nome-do-pai entra em substituição ao falo como objeto de desejo da mãe. Produzindo o nome-do-pai, a criança nomeará, metaforicamente, o objeto fundamental de seu desejo, embora sem o saber, já que o significante originário foi recalcado. Mas esse processo é passível de falha na estrutura simbólica, e implica na foraclusão do nome-do-pai, acidente que ressoa sobre a estrutura imaginária, dissolvendo-a e conduzindo-a à estrutura elementar, o que provoca a desestruturação imaginária, paradigmática da psicose.

A partir disso, pode-se pensar que há falha na estrutura simbólica na psicose. Sabe-se que o inconsciente de qualquer sujeito é estruturado na linguagem. Segundo Aragão e Ramirez (2004) a falha ocorre em reconhecer o "Nome-do-Pai" como significante em substituição ao significante originário do desejo da própria mãe. Dessa forma, pode-se pensar que a não inscrição do Nome-do-Pai no sujeito é o que pode estruturar a psicose. Percebe-se como necessário o entendimento do estádio espelho, incluindo o tema da foraclusão do nome do pai, chegando até o édipo. Neste último, mais se evidenciará a estruturação da psicose no sujeito.

Sabe-se, pela teoria Lacaniana, segundo Aragão e Ramirez (2004, p. 93), que no estádio do espelho, o Eu da criança estaria fragmentado ou esfacelado, pelo fato de não ainda se distinguir do "Eu originário" da mãe. A mãe ainda é o elemento totalizante na vida da criança e esta última se vê como única, não distinta daquela (primeiro tempo). Num segundo tempo, a criança apercebe-se que o Outro no espelho não é um outro real, mas uma imagem. Esta percepção leva a criança a não mais querer se apoderar dessa imagem, o que lhe "[...] permite distinguir a imagem do Outro da realidade do Outro". O terceiro momento, conforme os mesmos autores, é a junção dos dois primeiros numa igualdade: “[...] a dispersão do corpo esfacelado, numa totalidade unificada, representação do próprio corpo".

A partir disso, entende-se que esses três momentos do estádio do espelho apontam para o que vai se suceder no Édipo: a "solução" - a qual pode ser a inscrição correta da criança no mundo simbólico, pela inscrição paterna, ou "não solução" - a qual denotaria a falha dessa inscrição paterna, da instância da lei, caracterizando a psicose. Para Aragão e Ramirez (2004, p. 94) a instância da "lei" - paterna (o "Outro") - se presentifica no segundo e terceiro momentos do Édipo, a qual "intervirá na relação mãe-criança-falo sob a forma de privação".

Conforme Aragão e Ramirez (2004, p. 99), as duas etapas do édipo serão determinantes, pois, se o registro de castração não for internalizado pela criança, levando-a a perceber que ela não é o falo e de que não é portentora de um "poder" que a possa colocar na mesma posição do pai frente à mãe, não ocorrerá a instalação da metáfora paterna. E sem esta, a criança não conseguirá avançar para o estágio seguinte que seria a sua mobilização em direção a outros objetos substitutivos que não a mãe (identificação primordial). Se assim acontecer, a criança ficaria fixada, colocando-se como único objeto de satisfação de gozo da mãe, não conseguindo passar para a posição, a qual seria a solução para a problemática fálica: deixar “[...] de lado ser o falo para aceitar a problemática de ter o falo". 
As observações desses autores evidenciam o quão primoroso e estruturante é a função paterna para o ingresso do sujeito no mundo do simbólico, bem como suas relações com outros objetos e com a cultura, denotando a neurose. Porém seu "negativo" - a psicose - e o que seja específico dela, usando de uma terminologia freudiana, é a foraclusão do nome do Pai, ou seja, “[...] indica o tipo de negação envolvida no recalcamento: Verwerfung, cuja consequência para o sujeito é o retorno no real, já que a negação se deu pela via do simbólico" (Aragão e Ramirez, 2004, p. 100). A defesa, nesse caso da psicose, se daria justamente por meio do delírio e da alucinação (no real) como já escrito anteriormente pela exposição do caso Schreber (Freud, 1911/2010). Isto motivado pela injunção que aponta para o elemento faltante: Pai, na sua representação de instância da lei. Dessa forma, a foraclusão, como indica Solal Rabinovich (como citado em Aragão e Ramirez, 2009, p. 100), “[...] consiste, pois, afinal, em expulsar alguém fora das leis da linguagem".

\subsection{A Dimensão transferencial da psicose na clínica psicanalítica}

Sabe-se que a temática da transferência na clínica das psicoses é bastante delicada de ser tratada, pois distingue-se não só no conceito, mas no manejo em relação à neurose. No conceito, apesar das ressalvas a cada estrutura, pontuadas no capítulo anterior, as duas clínicas na psicanálise (da neurose e da psicose) convergem na medida em que buscam o tratamento para o sujeito e, no caso da psicose, o próprio sintoma (delírio) já é uma “[...] tentativa de cura ou de reconstrução” (Freud, 1924/2019, p. 274).

Freud (1912/2019), no texto sobre a "Dinâmica da Transferência", menciona que tanto na neurose, quanto na psicose ainda é possível a transferência, encaixando ambas no conceito (ainda) de "Psiconeuroses". No entanto, o insucesso da transferência na psicose pelo não entendimento adequado da forma de tratá-la ou de um manejo adequado, conforme Tenembaum (2010, p. 34), dá-se porque a “[...] conceituação desta é negativa e razão do insucesso terapêutico”. E, por uma razão bastante óbvia, conforme o mesmo autor: “[...] certos pacientes - os psicóticos - não serem sugestionáveis como os histéricos”. Seguindo ainda a linha de pensamento de Tenembaum (2010, p. 253), é na conferência XXVII, nos anos de 1916-1917, que as esperanças de Freud sobre a análise e tratamento de pacientes psicóticos terminam, pois não conseguem estabelecer a transferência, “[...] em consequência do abandono da catexia objetal e retorno desta ao ego, os psicóticos não reviveriam o conflito patogênico na relação analítica".

Retomando os estudos de 1912, onde também está presente o retorno desta catexia ao ego, Pinto (2007, p. 77) observa que Freud, antes de romper em definitivo com Jung em 1914, por seu monismo sob a teoria da libido, usa uma expressão do mesmo chamada de "Introversão da Libido", a qual será de fundamental importância para a clínica da psicose e o tema da transferência.

[...] no encontro entre Freud e Jung ou, mais especificamente, na controvérsia estabelecida sobre a teoria da libido, a nova etapa da psicanálise. A partir deste ponto, Freud pôde reorientar sua primeira teoria do dualismo pulsional, referindo-se ao autoerotismo e introduzindo o eu como uma instância de investimento libidinal e não mais apenas os objetos da pulsão. Ficou evidente, portanto, que o debate sobre a libido freudiana acarretou consequências cruciais para a concepção psicanalítica das psicoses, tanto que Freud reporta em "Sobre o narcisismo: uma introdução", que o conceito de narcisismo oferece uma alternativa à libido não sexual de Jung, presente nesses casos. Nesse mesmo texto, encontrase a crítica de Freud à concepção monista da libido presente em Jung, o que permitiu a Freud lançar as bases para uma futura dualidade pulsional necessária à sua concepção de que o conflito é estruturante do funcionamento psíquico.

Alude-se, conforme Tenembaum (2010), que a Teoria da Libido vai desembocar na obra "Sobre o Narcisismo: uma introdução" (1914) e, posteriormente na obra "Além do Princípio do Prazer" (1920). Esse resgate é importante compreender, pois no aspecto da dimensão transferencial do paciente psicótico, o terapeuta vai ter que percorrer, pelo manejo clínico da 
transferência, os meandros de um caminho traçado pela libido para se chegar à fonte do sintoma primordial no sujeito da psicose: a forclusão do nome do Pai - objeto de estudo peculiar da clínica psicanalítica voltada aos pacientes psicóticos.

Tenembaum (2010, p. 34), referindo-se a obra de Freud "Sobre o Narcisismo: uma introdução", define introversão da libido também se referindo ao campo da neurose. Mas o que é diferencial na clínica da psicose é que nesta o narcisismo "[...] é definido como retirada da libido da realidade com posterior reinvestimento no ego, para, finalmente, ser reinvestida delirantemente na realidade, etapa característica das psicoses". Assim, entende-se que a postulação da inversão da libido ao EU, marca um limite, não impedimento, para a relação transferencial do paciente ao analista. No entanto, como observado anteriormente, Freud não chegou alcançar em seus estudos esta compreensão, o que não quer dizer que tenha fechado portas para que a psicanálise pudesse compreendê-la no futuro, como assim de fato acontece.

Numa leitura desatenta do texto de 1912 "Sobre a dinâmica da Transferência" pode o leitor negar qualquer tipo de possibilidade de vínculo transferencial pela leitura da seguinte parte do texto de Freud, o que não seria apropriado: "Ali onde a capacidade de transferência se tornou essencialmente negativa, tal como nos paranoides, acaba a possibilidade de influência e de cura" (Freud, 1912/2019, p. 117). Por outro lado, Maciel (2008, p. 32) assevera, a partir do mesmo texto de Freud, que "[...] a transferência na psicose não é impossível, e sim de outra ordem, diferente da transferência que se coloca para as neuroses de transferência".

É essa "outra ordem" que se deve estabelecer na transferência nos casos de psicose, onde o analista, sobretudo, tem que ter a habilidade para diferenciar aquela (psicose) da clínica da neurose para não cometer o grande erro, que poderia ser fatal: levar um paciente psicótico, fora de crise - se viesse pedir tratamento analítico - à uma injunção, ou seja, pela má condução do tratamento, o paciente entraria em crise favorecido pelo próprio terapeuta (Calligaris, 2013). Nesse sentido, pode-se pensar ser importante situar o lugar e a forma tanto do analista como do paciente para que o vínculo da transferência na psicose se estabeleça. Na observação de Maciel (2008, p. 34), esses lugares se exprimem da seguinte forma pelo enunciado:

Como em qualquer prática psicanalítica, o trabalho acontece a partir do sujeito. Na psicose, não se trata de um sujeito dividido pela linguagem e que vai se endereçar ao analista como sujeito que supostamente sabe sobre seu sintoma. A psicose se endereça ao analista como sujeito para que testemunhe sobre sua experiência na linguagem e sobre a maneira como consegue se posicionar neste lugar.

Observa-se que o instrumento do paciente na relação com o analista será sempre por meio da linguagem, sem uma barreira simbólica. É no real! (Calligaris, 2013). E o analista será colocado numa posição de um “outro imaginário”, apontando para uma "relação especular, imaginária" (Maciel, 2008, p. 33). Isto porque o "Outro absoluto" foi foracluído. Lacan (19551956/1988, p. 295), no Seminário 3, chama a atenção para estes dois aspectos do que se entende por "outro imaginário" e "Outro absoluto", facilitando, assim, esta compreensão. O primeiro, designado pela letra minúscula “a”, o "outro imaginário”, é

[...] a alteridade em espelho, que nos faz depender da forma de nosso semelhante. O segundo, o Outro absoluto, é aquele ao qual nós nos dirigimos para além desse semelhante, aquele que somos forçados a admitir para além da relação da miragem, aquele que aceita ou se recusa na nossa presença, aquele que na ocasião nos engana... aquele ao qual sempre nos endereçamos.

Nesse sentido, compreende-se um avanço à temática do manejo, a qual intrinsecamente está vinculada pelo laço transferencial com a posição (lugar) onde analista e paciente se encontram. Nas palavras de Lacan (1957-1958/1998, p. 590): "Deixemos neste ponto, por ora, essa questão preliminar a todo tratamento possível das psicoses, que introduz, como vimos, a concepção a ser formada do manejo, nesse tratamento, da transferência".

Mendonça (2012, p. 73) compreende este aforismo lacaniano a partir de uma delimitação, encaixando-se na proposição deste trabalho que não quer ser um receituário aos que irão tratar a psicose: “[...] não temos nenhuma pretensão de fazer um 
manual de como lidar com o psicótico durante as sessões de análise, até porque sabemos muito bem da impossibilidade de tal tarefa no que concerne à experiência psicanalítica". Considera-se, também, que é pelo manejo que se tem uma ação direcionada ao sujeito: nesse caso, o paciente. O paciente psicótico não é o sujeito do "caos" pela sua (des-) estrutura, mas uma ordem do sujeito (Soler, 2007). Esse ponto de referência situa o analista na clínica psicanalítica das psicoses, bem distintamente da clínica das neuroses, consequentemente, no tipo de laço transferencial que se vai estabelecer. No caso das psicoses, o princípio número “1”, segundo Lacan (1958/1998, p. 592), no seu texto de “A direção do tratamento e os princípios de seu poder", é que o analista nunca deverá dirigir o paciente, já em relação à direção do tratamento, considera-se sob outra perspectiva: "O psicanalista certamente dirige o tratamento, o primeiro princípio desse tratamento, o que lhe é soletrado logo de saída... é o de que não se deve de modo algum dirigir o paciente... A direção do tratamento é outra coisa".

Se o analista não deve dirigir o paciente, como fica o manejo do paciente psicótico nessa situação? Não é estranho na indicação de Soler (como citado em Maciel, 2008, p. 35) que este deva assumir duas posições: “[...] posição de testemunha e a orientação de gozo". Na primeira, a autora indica que "[...] uma testemunha é um sujeito ao qual se supõe não saber, não gozar, e apresenta, portanto, um vazio no qual o sujeito poderá colocar seu testemunho" (Soler, como citado em Maciel, 2008, p. 35). Sobre esta primeira posição de Soler, buscando em obras de Freud que a fundamentam, pode-se elencar o texto de 1915 (2019) “Observações sobre o amor transferencial". Freud (1915/2019, p. 172) usa o termo "abstinência" na relação transferencial entre o analista e paciente. $\mathrm{O}$ alerta recai ao analista para que não se deixe invadir ou seduzir pelo gozo que muitas vezes lhe é dirigido pelo paciente, tonando-se empecilho para todo o tratamento analítico. E no caso da psicose, a demanda de amor do paciente também não deve ser suprida, pois, seria algo extremamente nocivo na medida em que o analista se aproximaria do que é faltante no paciente: o "Outro Absoluto" - como "outro invasivo".

Freud (1915/2019, p. 172) menciona que o

O tratamento precisa ser executado em abstinência; não me refiro aqui apenas à renúncia física nem à renúncia de tudo o que se deseja, pois isso talvez nenhum doente suportasse. Quero, antes, estabelecer o princípio de que a necessidade (Bedürfnis) e o anseio (Sehnsucht) devem ser mantidos na paciente como forças motivadoras do trabalho e da mudança e devemos evitar o abrandamento desses sentimentos por substitutos.

Passando à posição segunda, o analista vai ajudar na "orientação do gozo" no tratamento do paciente. Nesse sentido, pensa-se o quanto é possível aproximar os conceitos de orientação de gozo e "direção do tratamento" proposto por Lacan (19571958/1998). Para Maciel (2008), "é na direção do tratamento, com um diagnóstico preciso e uma construção das particularidades do caso, que se pode ter elementos que permitam acompanhar o sujeito na orientação do gozo" (Maciel, 2008, p. 36).

Esta indicação de Maciel (2008) de um "diagnóstico preciso" vem contribuir largamente para o que se vem trabalhando sobre o manejo clínico da psicose, especialmente se levar em conta os pacientes psicóticos que nunca tiveram uma crise, mas que procuram um atendimento clínico. Por outro lado, para os que estão na crise, acometidos de alucinações e delírios, apesar de ser mais evidente qualquer diagnóstico de psicose, o tratamento para ambos os casos será muito diferenciado, por suas particularidades. No primeiro caso, o diagnóstico para pacientes que nunca entraram numa crise possibilitaria tanto ao analista quanto ao paciente se situarem melhor pela transferência e o justo manejo, em vista da "estabilização" (Soler, 2007, p. 193).

Calligaris (2013, p. 14), no primeiro capítulo de seu livro "Introdução a uma clínica diferencial das psicoses", ressaltando a importância do diagnóstico e os desdobramentos destes pela transferência, menciona que a clínica psicanalítica não assume nem o caráter fenomenológico, tampouco o descritivo, mas o estrutural,

na medida que o diagnóstico se estabelece na transferência. O que não quer dizer que o diagnóstico seja um diagnóstico da transferência do sujeito... Em outras palavras, a clínica psicanalítica, por ser estrutural, quer dizer, por ser fundada 
na transferência (com a hipótese de que o laço transferencial desdobre a estrutura mesma do paciente), permite um diagnóstico da psicose mesmo na ausência de fenômenos classicamente psicóticos. Mais precisamente, a clínica psicanalítica pode falar de estrutura psicótica na ausência de qualquer crise psicótica e das suas manifestações.

Calligaris (2013, p. 17-18), exemplifica isto por meio do caso de um paciente que nunca entrou numa crise psicótica. E nas entrelinhas da descrição, o autor deixa muito claro a responsabilidade maior por parte do analista em razão do diagnóstico do paciente. O que, por si, já aponta para dificuldades que o analista pode encontrar neste percurso junto aos pacientes com este perfil, uma vez que estes podem se mostrar tão articulados com “simbolizações" muito parecidas com o neurótico e, se não for pela habilidade do analista em dispor-se a desdobrar a estrutura pela transferência, o diagnóstico poderia até se confundir com outros que não a psicose e, num extremo, fracassar qualquer possibilidade de estabilização ou ainda levá-los até a instalação da crise.

A partir de tudo isso, era um homem viável socialmente, embora para o neurótico médio, bastante misterioso.

A partir deste caso já podemos pensar algumas coisas: por exemplo, não podemos concluir, de modo algum, que um sujeito desse tipo não seja sujeito. Não podemos pensar que ele esteja tomado nos registros Imaginário e Real somente. Porque ele tem indubitavelmente uma significação de sujeito. Ele está tomado numa articulação simbólica, chega a circular nesse registro. Mas, se está tomado numa articulação simbólica, está tomado certamente de um jeito diferente do neurótico.

Calligaris (2013), evidencia que o diagnóstico está atrelado desde o início ao laço transferencial que o analista estabelece com um "sujeito" e não com um rótulo: "psicótico". O "rótulo" e o medo de ser o possível desencadeador da crise num paciente, leva muitos analistas a desistirem de qualquer tratamento possível da psicose (Mendonça, 2012). Nesse sentido, infere-se que o “medo", aqui, pode se referir à falta de condições técnicas, de manejo e, sobretudo, de um saber psicanalítico específico para este tipo de clínica.

Nesse ponto, o retorno ao texto de Freud (1912/2019), sobre as "Recomendações aos médicos que exercem a psicanálise", vale como ponto de apoio ao analista. Nele se observa um compromisso de "amor" do analista para com o paciente, somado às exigências que fazem parte da técnica, e que vai muito além de uma classificação sintomatológica na medida que se quer dar possibilidade de tratamento a esse sujeito que sofre mentalmente. Mas num outro texto de Freud (1915/2019, p. 168) "Observações sobre o amor transferencial" - esse tema fica ainda mais claro pelo exemplo que ele traz aludindo para a má conduta de médicos quando levam os pacientes (mesmo com uma intenção de "cura") a uma espécie de amor "apaixonado", que além de não ter nada a ver com a técnica psicanalítica, não favorece o tratamento - muito pelo contrário, criam-se obstáculos a ele.

Soube que alguns médicos que praticam a análise muitas vezes preparam os pacientes para o surgimento da transferência amorosa (Liebesübertragung) ou até mesmo os estimulam a se "apaixonar apenas pelo médico, para que a análise progrida". Não consigo imaginar uma técnica mais sem sentido do que essa. Com ela, extirpa-se do fenômeno o caráter convincente da espontaneidade e criam-se obstáculos para si próprio, que serão difíceis de remover depois.

Daí se percebe que o amor transferencial, não é o amor romântico, como muitos no tempo de Freud entendiam. Ele parte de uma relação do analista com a própria ética psicanalítica voltada para a direção do tratamento junto ao paciente. E no caso desse amor transferencial, respaldado pela técnica psicanalítica dirigido ao paciente com psicose, as regras de não poder impor barreiras e nem exigir do outro, nem de si (por uma resposta de cura: "furor sanandi”), ou um gozo mútuo, já são premissas básicas para o tratamento. Calligaris (2013) observa que a não resposta terapêutica de cura por parte do analista faz parte, também, do manejo, já que ele não pode alcançar ao paciente psicótico fora de crise - quando poderia desencadear a crise; e nos pacientes em crise, poderia ocupar o mesmo lugar do Grande Outro, invasivo, impossibilitando qualquer tratamento. 
Um postulado de Nasio (1999, p. 14) na obra "Como trabalha um psicanalista", mesmo que o autor refira esta mais ao campo da neurose, é interessante sua relação com o tratamento das psicoses, pois, existe uma "[...] demanda de amor aberta e suscitada pelo quadro transferencial”. Já Albino (2021, p. 455) vai dizer que o analista, na relação transferencial, “[...] ele é uma presença viva, que chama para si a responsabilidade de construir um laço amoroso capaz de, passo a passo, criar uma atmosfera de confiabilidade e persistência, que pode fortalecer o ego frágil que caracteriza o psicótico". Nesse sentido, entende-se que o amor transferencial (na psicose) como resposta do analista, mesmo na posição de testemunha, não é vago. Ele está na razão de um saber do analista (pela psicanálise) voltado para à instância psíquica, precária, do paciente, atribuída pela falta do significante "Nome-do-Pai”. O qual, nas palavras de Meyer (2008, p. 305), é “[...] responsável pela barra do Outro, que organiza a cadeia significante no inconsciente".

Compreende-se, dessa forma, que a falta da lei, que não é simbolizada pelo paciente, não pode ser exigida, nem suprida pelo analista, requerendo, por parte deste último, essa posição de testemunha na alteridade. Ademais, é mister saber, segundo Tenembaum (2010, p. 254), que “[...] os pacientes psicóticos buscam a si mesmos por intermédio de mentes auxiliares cooptadas em suas relações interpessoais, incapazes que estão de mentalizar suas experiências”. Sob esse prisma,

O psicótico testemunha sua condição de objeto perante o Outro, interpretando os fenômenos e incutindo a eles algum sentido. Essa interpretação pode se tornar uma construção delirante e ela será facilitada quando o psicótico encontra no analista este Outro menos invasivo (Maciel, 2008, p. 35).

Quinet (2018, p. 133) traz um outro imperativo ao analista no processo clínico-terapêutico da psicose (em qualquer fase que se encontre o paciente - dentro ou fora da crise): ele será constituído como "barreira" por seu paciente. Este mesmo autor ajuda a aclarar esta afirmação, pois há algo aqui que se constituí como um paradoxo ao se observar que a demanda do próprio paciente psicótico ao analista (esse outro menos invasivo), pela falta da barreira simbólica, é o desejo de "barramento" do "Outro absoluto" -

[...] barreira ao Outro que o persegue, que fala em sua cabeça, que o manipula ou que o olha na rua. Trata-se de um pedido de asilo para exilar-se do Outro. Esse pedido também é feito ao asilo, ao hospício, onde a barreira é de concreto como se o Outro pudesse ser barrado na porta.

Entende-se a complexidade desse arrazoado se houver uma confrontação entre a posição do analista como testemunha (compreendida como posição passiva) e, por outro lado, a posição de alguém que barra (ativa). Acima foi escrito que o psicanalista dirige o tratamento, porém não deverá dirigir o paciente (Lacan, 1957-1958/1998). Pensando em uma possível associação entre o que foi descrito por Soler (Soler, como citado em Maciel, 2008) e Lacan (1957-1958/1998), vê-se que a posição de testemunha do analista não se furta do seu papel ativo, pois tem o entendimento e clareza de sua função na direção do processo.

Quinet (2018, p. 135), trazendo o caso Schreber à pauta, na relação (em estado de delírio) transferencial com o Dr. Flechsig, elucida sobre a "erotomania mortífera". Esta, quase sempre, pode acometer os pacientes psicóticos - como Schreber. Se não houver um "barramento", como sinônimo de um manejo adequado, o próprio analista pode avalizar, caucionar "[...] esta posição que é, no mínimo, insustentável, pois, ela implica que o analisante se mantenha em posição de objeto de gozo do Outro. Aceitar essa posição em que o psicótico situa o analista implica aceitar ocupar o lugar do supereu terrível e gozador”.

Retomando o segundo aspecto do manejo defendido por Soler, a posição do analista como aquele que vai ajudar na “orientação do gozo", percebe-se que este se afina com aquilo que Lacan propõe como a "direção do tratamento" e não do sujeito (Lacan, 1957-1958/1998). O analista, dirigindo o tratamento, é alguém capaz de barrar o gozo do paciente psicótico na intenção de que o significante "Nome do Pai" possa advir (Quinet, 2018)", mas na condição de testemunha. Nesse sentido, parece que 
aqui as posições as quais Soler (como citado em Maciel, 2018) se refere, entrelaçam-se, para que o objetivo terapêutico do tratamento possa ir se consolidando mediante um processo em que ambos (paciente e analista) estão implicados pela transferência. Quinet (2018, p. 138) faz um alerta ao analista para não descuidar nunca da posição de testemunha na orientação do gozo do paciente, pois, de outra forma, o mesmo pode se constituir como o "Outro devorador". O mesmo autor afirma que o analista deveria ser como que um "secretário do alienado", mas com implicações ativas pela direção do tratamento.

Trata-se de secretariar, constituindo-se o analista como testemunha da relação do sujeito com o Outro. Entretanto, entre a posição de testemunha e a posição de perseguidor, entre ser seu secretário e ser o objeto de sua erotomania, não há efetivamente uma distância muito grande. Podemos dizer que há uma tensão entre essas duas posições. Pois, ocupar o lugar do Outro absoluto para o psicótico é uma consequência lógica da análise, é assim que se manifesta a sua transferência. Daí a dificuldade do analista em não aceitar essa posição e ao mesmo tempo manter o laço analítico.

Tais observações de Quinet (2018) desvelam muito da necessidade do papel ativo do analista no tratamento. É uma condição sine qua non se se quiser pensar numa possível intervenção estabilizadora e terapêutica do paciente psicótico. Desse modo, pela tendência do paciente a dispor-se pela invasão do gozo do Outro não barrado, o analista será o outro barrado no sentido da orientação desse gozo desenfreado (Maciel, 2008). Sem essa barreira, o paciente se coloca numa posição de objeto pela Demanda imaginária do Grande Outro. Calligaris (2013, p. 93), afirma que

[...] o sujeito recebe, vindo do Outro, é um pedido não negociável simbolicamente, ao qual ele responde ou com uma entrega no Real ou com uma entrega alucinada. Mas esta relação prevalente não deixa de dialogar com tentativas assíduas de constituir uma metáfora delirante respondendo à exigência paterna.

Dessa forma, há de se pensar que o analista enfrenta com o paciente psicótico, por essa posição de barramento ou de orientação do gozo, o desafio contínuo de contribuir em esvaziar o gozo do Outro que o paciente lhe atribui. Quinet (2018, p. 138) afirma que “A 'vantagem' é a própria transferência... Se a única maneira de cingir o real é por intermédio do simbólico, é pela fala que algo de esvaziamento do gozo pode vir a se produzir”. Essa pontualização de Quinet (2018) realça o aspecto da ferramenta, por excelência, do analista na orientação do gozo de um paciente psicótico: é a fala dele que vai dirigir e orientar o sujeito dividido pela linguagem, mesmo quando este está no delírio.

Por meio do exemplo de um paciente citado por Maciel (2008, pp. 36-37), vê-se a ilustração desse "poder" da fala do analista, quando este, na relação transferencial - já consolidada, ajuda na orientação do gozo do paciente:

Lúcio é um paciente psicótico atendido em consultório particular há dois anos. O tratamento analítico é realizado paralelamente ao acompanhamento psiquiátrico realizado em outro local. Em determinado momento, Lúcio pára de tomar a medicação antipsicótica seguindo instruções de seu psiquiatra. Na medida em que este psiquiatra se localiza numa posição muito particular para Lúcio, este é levado a abrir mão do remédio sem a menor possibilidade de questionamento da conduta. O momento que vive então é bastante difícil. Lúcio, que já havia passado por diversos surtos desde a adolescência, estava estabilizado nos últimos anos, volta a apresentar fenômenos elementares com grande frequência. Durante o tempo em que fica sem a medicação, é disponibilizado a ele um maior número de atendimentos, na medida em que afirma ao analista que "tem muita coisa acontecendo e eu preciso conversar mais aqui" (sic). Comparece aos atendimentos e conta diversas manobras que precisa fazer em seu dia-a-dia, principalmente no que diz respeito à convivência com os vizinhos. Na medida em que neste momento é apresentado a ele o recurso de ir mais aos atendimentos e considerando que ele está muito invadido por fenômenos elementares, o analista se coloca como uma testemunha do que este paciente precisa "conversar". O silêncio do analista é bastante recorrente, mas sempre indicando uma atenção, ou seja, mostrando que está ali presente e disponibilizando um espaço de não saber onde o paciente pudesse depositar seu saber construído. Durante este período, Lúcio opta pela primeira vez por não ser internado e aposta em fazer uso deste espaço que lhe é disponibilizado. Consegue manter sua convivência social, localizando o espaço do tratamento como o espaço para onde pode direcionar seu delírio... A participação na Igreja é um fator importante na vida deste paciente, desde o desencadeamento da psicose. Neste lugar vem sendo constantemente 
convocado numa posição fálica, a partir da qual não pode responder, sendo, portanto, necessárias intervenções em sua participação. Diante das convocações que a Igreja faz, Lúcio responde com o delírio, mas esta maneira de resposta é para ele muito invasiva e sem contenção. Ele tem medo de não ter controle sobre o delírio místico e tem buscado outras vias de trabalho. Sobre sua relação com a Igreja afirma: "Eu acho que o mais importante pra mim é a Igreja, mas é o mais difícil também. Porque eu tenho de um lado a Igreja e de outro a minha família [...] Eu fico assustado quando eles (na Igreja) me chamam pra ser coordenador. Poxa, eu acabei de sair de um hospital psiquiátrico" (sic). Essa e outras falas do paciente indicam que a Igreja tem sido para ele um Outro sem lei, perseguidor. Diante disso, o analista se coloca de maneira ativa, dizendo que é preciso que ele não vá tanto à Igreja e que ele pode escolher como vai acontecer sua participação, podendo se afastar quando achar necessário. Quem indica que a relação com a Igreja envolve um excesso é o próprio paciente. Ao dizer isso ao analista, coube a este recolher esta fala, este elemento simbólico que ele liga ao que acontece com ele, e devolver a ele na forma de uma interdição.

Compreendendo o que foi referenciado, é esclarecedor que a interpretação esteja ligada, essencialmente ao próprio paciente. A interdição do analista, na orientação desse gozo, que não se mostra numa mesma posição invasiva desse Grande Outro, embora colabore para que o paciente se torne mais consciente de sua fragilidade mental ou egóica e melhore "[...] sua capacidade de mentalizar as situações de vida pelas quais passou, passa e vai passar" (Tenembaum, 2010, p. 259). Nesse sentido, quão elementar é pensar que esse tipo de clínica psicanalítica seja sempre uma contínua construção em vista do ser e de suas especificidades. Aqui não é somente o "ser" do paciente - o sujeito da psicose, também do analista, da psicanálise, dos outros seres, o ambiente e suas composições. São esses sujeitos, entrelaçados, não misturados, que formam uma sociedade e cultura, visando estabelecer vínculos possíveis e realizações, enquanto possíveis (Freud, 1930/2010). Pode-se perceber que todos são suscetíveis ao que adoece e o que faz a vida fenecer em qualquer momento da vida - em menor ou maior grau. E o que favorece a "cura" é o que se vê (enquanto humanos em relação) pela via transferencial do que não se vê: amor.

Freud em carta a Jung, em 06/12/1906 (1976, p. 53), escreve:

Poder-se-ia dizer que a cura (psicanalítica) é essencialmente efetuada pelo amor. E a transferência, na realidade, proporciona a prova mais convincente - a única de fato irrefutável - de que as neuroses são determinadas pela história de amor do indivíduo.

Por esta frase de Freud, mesmo que ele aqui se refira ao terreno das neuroses, entende-se que seja extensivo, também, ao das psicoses, uma vez que os vínculos transferenciais estabelecidos sob essa égide do amor, imprimem o caráter essencial do humano. Tenembaum (2010, p. 42-43) desmistifica aqueles que pensam que os psicóticos sejam incapazes de estabelecer relações com os objetos externos ou de que as relações humanas estabelecidas com eles não tenham seu cunho terapêutico.

A ideia de que o psicótico não se relaciona com os objetos (externos), mas consigo mesmo, está incompleta e tem por base o equívoco de se pensar que a relação objetal é um fim em si mesmo. Não é. As experiências de vínculo, as relações objetais, são os meios pelos quais realizamos a experiência humana. O psicótico não se relaciona narcisicamente consigo; por meio das pessoas e coisas ele busca a si mesmo. Daí suas relações objetais serem necessariamente diádicas. A experiência clínica tem me mostrado que o desligamento dos objetos externos só ocorre nas situações de falta de contato humano, seja nos asilos, nas ruas ou dentro de certos grupos familiares.

\section{Considerações Finais}

A escolha do tema abordado no decorrer deste trabalho não foi mero acaso de um estudante de psicologia em término de curso. Foi, na verdade, fruto de um desejo frente à necessidade na prática clínica de estágio. Situação esta que, na maioria das vezes, leva aos atendimentos de pacientes neuróticos e, o incomum, pacientes psicóticos. Em consequência disto, há uma espera de uma estrutura, com um arcabouço de conhecimentos aprendidos durante o curso para ser colocado à disposição no tratamento do que é "habitual" (neurose), fugindo da "exceção" (psicose). Apesar do paciente não vir com um diagnóstico 
(quase sempre), ocorre de imediato a suposição de se tratar de mais um neurótico. No entanto, a prática clínica sempre surpreende a cada dia, convocando o analista a abrir-se ao inesperado.

No caso do "inesperado" - aqui não se está falando de um atendimento de paciente psicótico na iminência de um surto ou em surto, demandando um tratamento mais especializado em um ambiente favorável, mas de alguém, como foi citado ao longo deste trabalho, que é psicótico - que por vezes nunca tenha surtado, podendo apresentar certas simbolizações - muito características de um neurótico. Esse paciente pode chegar ao consultório, exigindo do analista não só uma formação mais específica, mas um lugar na transferência, trato e manejo bem diferenciados do neurótico. Sem esse respaldo, pode o analista ser invadido pelo "medo" e suposições de fracasso, sem avançar àquilo que the compete na sua função.

Ademais, a evolução da psicanálise desde Freud, com autores como Lacan e outros cujos nomes de alguns foram citados, provam que é possível, sim, o contributo psicanalítico no tratamento da psicose com pacientes que nunca foram acometidos de um surto, ou até mesmo os que já tiveram. Pelo que foi analisado, para estes últimos, a exigência é ainda maior. Mas, via de regra, tanto a neurose quanto a psicose são estruturações do sujeito em vista de uma defesa - mesmo que o saber de um e de outro sejam aplicados diferentemente em cada um dos casos. Mas o sujeito da psicose, pela falta ou forclusão do Nome-do-Pai, parece requerer mais a ajuda do analista, na transferência, pela necessidade de alguém que barre o Outro devorador, enquanto que o neurótico, que é capaz de simbolizar, possui mais recursos de defesa.

Dessa forma, é no "campo fértil" e ao mesmo tempo pedregoso, da clínica psicanalítica das psicoses, que muitos analistas experienciam em pacientes esse estado de vulnerabilidade maior, em que as informações nem sempre obtidas, são suficientes sem uma prática adquirida ao longo do tempo. Fica claro, portanto, que é o conhecimento, associado na direção do tratamento, pela transferência, que possibilita a adequação de um justo manejo ao paciente. Constata-se aqui o tripé psicanalítico apontado por Freud (1919/1974): análise pessoal, supervisão e estudo teórico. Para além da prática clínica, nunca se deve deixar de considerar esses três tópicos, pois são eles o suporte de amparo principalmente ao analista e, por via de consequência, ao paciente.

Seguindo esse "tripé", o crescente gosto pela psicanálise é constantemente suscitado, e não diminuído, nem mesmo frente às frustrações que, sabe-se, podem ocorrer no decurso do processo analítico, haja vista a complexidade do tratamento das psicoses. Nesse itinerário do "inesperado", o "não saber" preciso sobre a psicose não pode ser obstáculo para o "saber" sobre ela. Ao contrário, é a alavanca de uma construção que se dá a partir de cada indivíduo, pela sua subjetividade, na relação transferencial com o analista. Dessa forma entendida, de fato, o analista sempre estará usando de suas forças para o que ainda não se sabe, em vista do bem terapêutico que ele pode oferecer pelo seu trabalho dedicado ao paciente com essa demanda.

A psicanálise criada por Freud nunca pretendeu ser um manual conclusivo aos analistas com um ponto final ao que seu próprio criador compilou nos seus anos de história e práticas clínicas. Até porque a psicanálise se investe do sujeito (de sua subjetividade), mas também da cultura, em constantes transformações. E quem a escolhe (a Psicanálise), transmite posteriormente um estilo que lhe é próprio nas revoluções da cultura, já dizia Lacan (1957/1998).

Um estilo não deixa de ser algo próprio do sujeito com base nas suas construções e desejos. Nesse sentido, o desejo de saber mais sobre o pouco que até então se sabia a respeito da psicanálise, especificamente em relação à psicose, foi fator determinante para a escolha da temática: fundamentos psicanalíticos na construção da subjetividade na psicose. Sobre o primeiro capítulo, onde se delineou o conceito, trazendo a evolução dos fundamentos da clínica psicanalítica das psicoses, com alguns casos ilustrados, foi a possibilidade de vir a situar-se na vasta gama de textos de Freud, cuja temática (das psicoses), por vezes, aparece de forma pulverizada, também em outros autores pós freudianos os quais igualmente perceberam a importância desse tipo de clínica. De modo que, pela revisitação desses autores ao "Pai" da psicanálise, fica nítido o quão atual ainda são os seus textos e o quanto são aprimorados na diligência de um bem terapêutico que possa vir a ser ofertado ao paciente e à sociedade - na medida que melhor entende e consegue reintegrá-lo à mesma. 
Já o segundo capítulo, explorando mais a dimensão da transferência dos pacientes psicóticos, claramente reforçou ser possível o tratamento, desde que haja um sábio e justo manejo clínico. Para isso, a pessoa do analista é aquela fundamental e necessária presença que testemunha e orienta o gozo do paciente. Mas é também aquele que ajuda na construção de um saber social mais humano, experienciado na realidade de alguém que pode ser "deferente" na sua estrutura. Seria muito mais fácil mover-se no terreno das diferenças, se não houvesse aplicação de rótulos que separam.

O "louco" (psicótico), foi por muito tempo separado, para não dizer banido, do mundo dos tidos como "certos". E esse degredo possibilitou classificações na ordem das subjetividades pela própria sociedade que, do contrário, não existiriam. Assim, além da pertinência teórica deste trabalho de pesquisa realizado no campo da psicose, chega-se ao ápice que ela aponta na direção do que ainda precisa ser feito, ou seja, para a construção de um renovado saber onde se saiba situar o "louco", o psicótico como sujeito em sua, em "nossa" história, a fim de assegurar um lugar que lhe é próprio - não por merecimento de um estado de "sanidade", cuja sociedade lhe confere como justo.

E se a história, pelo que se pode constatar, construiu um distanciamento, quando não a falta de tratamento e cuidados apropriados ao "louco", por um saber nada simpático sobre este, é através da história que precisa ser descontruída por intermédio de um justo saber mais apropriado e humano. Infere-se que essa dívida histórica ainda se encontra pendente, carecendo muito do trabalho qualificado dos profissionais da área da saúde mental, uma vez que o saber, especialmente nesta área, tem que gerar tanto o cuidado pelo outro como a capacidade de poder ajudar na transformação das consciências. Sendo que o "outro", aqui, é sempre entendido por "humano", de modo que o sujeito da psicose não é dessemelhante do que é humano, apenas diferente em sua estruturação, merecedor, portanto, de atenção e cuidados profissionais especializados.

\section{Referências}

Albino, A. (2021). Transferência ativa: um manejo clínico no tratamento das psicoses. REFACS. 9 (2), $450-462$.

Aragão e Ramirez, H. H. (2004). Sobre a metáfora paterna e a foraclusão do nome-do-pai: uma introdução. Mental, 2 (3), 89-105.

Briggs, R. \& Rinaldi, D. (2014). O sujeito psicótico e a função do delírio. Latino Am. psicopatologia fundamental, 17 (3), $416-430$.

Burgarelli, S. R. \& Santiago, J. (2009). A psicose de Lacan a Freud. Arq. bras. psicol., 61 (1), 143-152.

Calligaris, Contardo (2013). Introdução a uma clínica diferencial das psicoses (2a ed.). Zagodoni.

Freud, S. (1891/2016). Sobre a concepção das afasias. Um estudo crítico. Autêntica.

Freud, S. \& Jung C. G. (1906/1976). Freud/Jung correspondência completa, org. William McGuire. Imago.

Freud, S. (1911/2010). Observações psicanaliticas sobre um caso de paranoia relatado em autobiografia: ("O caso Schreber"): artigo sobre técnica e outros textos. São Paulo: Companhia das Letras, vol. 10.

Freud, S. (1912/2019). Fundamentos da clínica psicanalítica (2a ed.). Autêntica.

Freud, S. (1919/1974). Sobre o ensino da psicanálise na universidade. In: Obras completas. Alianza.

Freud, S. (1924/2019). Neurose, Psicose, Perversão. Autêntica.

Freud, S. (1930/2010). O mal-estar na civilização, Novas conferências introdutórias à psicanálise e outros textos. In: Edição Brasileira das Obras Completas de Sigmund Freud. Companhia das Letras.

Gil, A. C. (2006). Como elaborar projetos de pesquisa. (4a.ed.). Atlas.

Lacan, J. (1955-1956/1988). O Seminário. Livro 3: As psicoses. (2a. ed.). Jorge Zahar.

Lacan, J. (1957/1998). A psicanálise e seu ensino. In: Escritos. Jorge Zahar.

Lacan, J. (1957-1958/1998). De uma questão preliminar a todo tratamento possível da psicose. In: Escritos. Jorge Zahar.

Lacan, J. (1958/1998). A direção do tratamento e os princípios de seu poder. In: Escritos. Jorge Zahar.

Laplanche, J \& Pontalis, J. B. (2016). Vocabulário da psicanálise (4a. ed.). Martins Fontes.

Maciel, V. S. (2008). A transferência no tratamento da psicose. Mental, 6 (10), 31-40. 
Research, Society and Development, v. 10, n. 10, e136101018738, 2021

(CC BY 4.0) | ISSN 2525-3409 | DOI: http://dx.doi.org/10.33448/rsd-v10i10.18738

Mendonça, R. L. (2012). o inconsciente a céu aberto e a transferência: o secretário do alienado como manejo clínico na psicose. PPGPSI-UFSJ.

Meyer, G. R. (2008). Algumas considerações sobre o sujeito na psicose. Ágora: Estudos em Teoria Psicanalítica (online), 11 (2), 299-312.

Minayo, M. C. S. (2003). Pesquisa social: teoria, método e criatividade (22a. ed.). Vozes.

Nasio, J. D. (1999). Como trabalha um psicanalista. Zahar.

Nasio, J. D. (2001). Os Grandes casos de Psicose. Zahar.

Pinto, K. M. (2007). Crônica de um fim anunciado: o debate entre Freud e Jung sobre a teoria da libido. Ágora, 10 (1), $75-88$.

Quinet, A. (2018). Teoria e clínica da psicose (5a. ed.). Forense Universitária.

Rother, E. T. (2007). Revisão sistemática X revisão narrativa. Acta Paulista de Enfermagem (online), 20 (2), v-vi.

Santos, T. C. \& Oliveira, F. L. G. (2012). Teoria e clínica psicanalítica da psicose em Freud e Lacan. Psicol. estud., 17 (1), $73-82$.

Soler, C. (2007). O inconsciente a céu aberto da psicose. Zahar.

Tenembaum, D. (2010). Investigando psicanaliticamente as psicoses (2a. ed.). Rubio. 